\title{
A XP e o Itaú Unibanco: dos Produtos de
} Investimento a Desbancarização

\section{XP and Itaú Unibanco: From the Products of \\ Investment to the "Desbancarização" Process}

\author{
Raul Beal Partyka \\ Jeferson Lana \\ Rosilene Marcon
}

Este caso para ensino apresenta a narrativa da aquisição da XP Investimentos pelo Itaú Unibanco. O banco ofertou a compra da XP Investimentos. Este movimento ocorreu pouco antes da corretora pedir o registro para realizar seu IPO (Oferta Inicial de Ações, sigla em inglês) na bolsa de valores brasileira (B3). O objetivo do estudo é impulsionar as discussões da operação de aquisição para os temas de estrutura de governança e a teoria dos custos de transação em meio a inovação tecnológica no mercado financeiro brasileiro. Pelo lado da XP o plano era claro: em uma tacada só, ficar com o ativo e eliminar um concorrente, podendo agora não apenas sonhar em ser o maior grupo de investimentos do Brasil. Já para o Itaú Unibanco - maior player do mercado - passa a ter a carteira da XP pronta e elimina um concorrente que lhe tirava market share. O caso indica discussões sobre a lógica por trás da aquisição da XP pelo Itaú Unibanco. Ainda, permite indagar se não seria capaz o maior banco do Brasil, desenvolver tais capacidades adquiridas da corretora, além de questionar se as capacidades internalizadas da XP são tão valiosas a ponto de tamanho investimento.

Palavras-chave: Bancos, Corretoras, Teoria do custo de transação, Inovação tecnológica, Cenários econômicos.

This teaching case presents the narrative of the acquisition of $\mathrm{XP}$ Investimentos by Itaú Unibanco. The bank offered to buy $\mathrm{XP}$ Investimentos. This movement occurred shortly before the broker asked to register for its IPO (Initial Offering of Shares, acronym in English) on the Brazilian stock exchange (B3). The objective of the study is to encourage discussions of the acquisition operation for the themes of governance structure and the theory of transaction costs amid technological innovation in the Brazilian financial market. On the XP side, the plan was clear: in one stroke, stay with the asset and eliminate a competitor, and now you can not only dream of being the largest invest-

Recebido em: 07/02/2020 Aprovado em: 20/04/2020

Raul Beal Partyka (iD

raul.partyka@fgv.edu.br

Mestre em Administração de Empresas - Univali

MSc. in Business Administration - Univali Fundação Getúlio Vargas - Escola de Administração de Empresas de São Paulo São Paulo/SP - Brasil

Jeferson Lana iD

jlana@univali.br

Doutor em Administração de Empresas FGV/EAESP

$P h D$ in Business Administration - FGVI EAESP

Universidade do Vale do Itajaí

Biguaçu/SC - Brasil

Rosilene Marcon (iD

rmarcon@univali.br

Doutora em Engenharia de Produção UFSC

PhD in Production Engineering - UFSC

Universidade do Vale do Itajaí

Biguaçu/SC - Brasil 
ment group in Brazil. For Itaú Unibanco - the largest player in the market - it now has the XP portfolio ready and eliminates a competitor that took its market share. The case indicates discussions about the logic behind Itaú Unibanco's acquisition of XP. Still, it allows asking whether the largest bank in Brazil would not be able to develop such capacities acquired from the broker, in addition to questioning whether XP's internalized capacities are so valuable to the point of such investment.

Keywords: Banks, Brokers, Transaction cost theory, Technological innovation, Economic scenarios.

\section{O Caso}

"Era só um bate-papo em que comentamos o processo de abertura de capital (IPO). Mas a conversa foi boa. Tive a oportunidade de um encontro com Roberto Setubal para contar um pouco mais sobre nosso projeto", explica Benchimol, CEO do Grupo XP, ao falar sobre a primeira reunião de onde partiu e definiu a transação entre Itaú Unibanco e XP Investimentos. "Houve uma super empatia, teve uma química legal”, ainda definiu Benchimol, que conhecia Setubal, mas não era próximo. A partir daí, seguiram-se uma série de encontros com a cúpula do banco, que reuniu também Pedro Moreira Salles, também copresidente do conselho do Itaú, e Candido Bracher, presidente da Diretoria do Itaú. (DYNIEWICZ; LUZ, 2017).

O encontro com o Copresidente do conselho do Itaú foi há cerca de dois meses e meio antes do dia 10 de maio de 2017, quando o Banco Itaú Unibanco confirmou que negociava a aquisição da participação minoritária na XP, mas sem nenhum acordo firmado. Enquanto isso, a XP Investimentos informava que seguia com o IPO na B3 (REDAÇÃO VEJA, 2017).

Era só uma questão de tempo. Negócio fechado. A compra da XP faz lembrar daquela ocorrida em 2009, quando o Itaú adquiriu a seguradora Porto Seguro (GRADILONE; GALEMBECK, 2017) - ambas com cláusulas de opção de compra do controle no longo prazo (SAMOR, 2017). Naquele momento, todos a cobiçavam, mas o Itaú foi quem realmente ofereceu o melhor projeto de futuro: autonomia e manutenção da fórmula de sucesso do negócio. Horas de reuniões, muitas delas na maior avenida corporativa do Brasil, a Faria Lima, culminaram no desfecho positivo da compra da seguradora. No caso da XP, o negócio confirmou-se na quinta-feira, 
dia 11 de maio de 2017. Durante as conversas, o CEO do Itaú teria apontado a possibilidade de colocar Guilherme Benchimol, CEO e fundador da XP, na corrida pela sucessão presidencial do banco. (GRADILONE; GALEMBECK, 2017).

O espanto do mercado, diante da transação, veio por dois motivos: a empresa vinha preparando seu IPO (oferta inicial de ações, na sigla em inglês) e, principalmente, havia crescido de forma acelerada nos últimos anos ancorada no discurso de "desbancarização". Benchimol julgou ter agora o melhor dos mundos; "tenho a liberdade de controle da empresa e o Itaú me dando credibilidade. Quem mexe com investimento tem de expor credibilidade. Quando a gente faz o negócio com o Itaú, a gente endereça todas essas questões (credibilidade e governança). Abrir capital é um desafio enorme. Há momentos em que a ação cai com as crises. Aí aparece uma oportunidade para captar dinheiro a um preço parecido com o que achávamos que íamos captar no mercado, podendo continuar com capital fechado, e o sócio ainda agrega mais credibilidade do que o mercado." (DYNIEWICZ; LUZ, 2017).

A mensagem que o Itaú passa é que não entrou como gestor, mas sim como investidor. Suas declarações visavam ser a maior empresa de investimento no Brasil em dez anos. Com a compra da XP isso mudou para que o objetivo seja atingido em cinco anos. (DYNIEWICZ; LUZ, 2017). Ainda, para o banco, a aquisição visa estancar a recente perda de investimentos de clientes mais exclusivos além de criar uma barreira no crescimento de concorrentes da XP. (GRADILONE; GALEMBECK, 2017).

A conselheira do CADE, Cristiane Alkmin Junqueira Schmidt em seu voto (CADE, 2018), relata que o real interesse do Itaú na compra da XP pode ser: (1) que o lucro da XP não seja manipulado pela XP após 2024 (fazendo-o inflar artificialmente para vender a empresa mais cara), (2) que o preço da XP seja de fato justo, para o Itaú não ter perda financeira e (3) que ela seja a dona da XP futuramente, para garantir ter em suas mãos o Maverick, que tem levado parte de seus clientes; e (4) o real interesse do Itaú na compra da XP relaciona-se com o interesse no que a XP tem de mais valioso: a sua base de clientes atual e futura, lembrando que parte da base atual era do Itaú e parte da futura poderia ser também. O Itaú quer, assim, minimizar a sua perda da migração de clientes do Itaú para a XP.

A XP Investimentos pediu registro para uma oferta inicial de ações (IPO, na sigla em inglês), no dia 10 de maio de 2017, horas depois de admitir que conversa 
com o Itaú Unibanco sobre uma possível venda de participação na companhia (ALVES, 2017). Pouco a pouco, a operação começou a ser desenhada, e ganhou tração nos últimos 45 dias. "O foco era o IPO (abertura de capital), mas, há um mês e meio, a gente já estava convicto de que queria a operação (com o Itaú). Como não tínhamos a certeza de que ela ia sair, levamos o processo de IPO em paralelo porque era a única coisa que tínhamos na mão se tudo desse errado." (DYNIEWICZ; LUZ, 2017).

Também em 10 de maio, a XP confirmou a intenção de vender uma participação minoritária, mas disse que irá continuar com o seu plano da venda de ações na B3. O valor pago pela participação, segundo cálculos da Empiricus Research, aponta para um valuation de 25 a 30 vezes os lucros (KAHIL, 2017). Para a ConseIheira Cristiane, do CADE, a XP exerceria a sua PUT por, ao menos, duas razões: (1) seja porque a XP entende que o valor da empresa é maior hoje do que ela espera que seja no futuro, logo, vale vender hoje; (2) seja porque a XP esteja em discordância com o Itaú, já que o Itaú terá diversos direitos a vetos, indicará 2 membros no Conselho de Administração da XP, assim como o seu CFO e o Conselho Fiscal. Ou seja, é "influência a perder de vista" para um simples minoritário.

\section{O Contexto}

Dinheiro físico ainda é o principal meio de pagamento ao redor do mundo. O dinheiro de bancos comerciais traz segurança, permite transações remotas e o acesso a outros serviços financeiros. No entanto, para a população de países emergentes e economias em desenvolvimento, esse tipo de serviço não é muito acessível. Os sem banco (unbanking) moram longe das agências bancárias e o custo desses serviços é muito alto (NASCIMENTO, 2020).

$\mathrm{O}$ termo unbanking refere-se a algo bastante comum no cenário financeiro mundial. O Banco Mundial estipulou que em 2011 havia 2,5 bilhões de pessoas sem banco no mundo. Já "desbancarização" é o movimento de fuga dos clientes dos bancos tradicionais, também chamados de grandes bancos. Ainda "de-banking" é uma prática que os bancos realizam quando encerram as contas com clientes considerados "alto risco", minimizando sua própria exposição ao risco. Em 2017, com o 
surgimento das fintechs - startups da área de serviços financeiros -, o número caiu para 1,7 bilhão de pessoas. No Brasil, o IBGE estimou 60 milhões de "desbancarizados", quase metade da população economicamente ativas - 110 milhões. Mas com um alto volume de transações, as classes B e C, antes negligenciadas por não conseguirem comprovar renda, passam a ser um novo mercado a se conquistar. (OLD, 2019). Por outro lado, o economista-chefe do Itaú Unibanco, Mario Mesquita, destaca que um possível aumento da "desbancarização", no caso de uma nova CPMF, pode ocorrer. Isso porque as pessoas buscariam por novas formas de pagamento, até mesmo aquelas sem fiscalização (PASSARO, 2019).

Inicialmente, a XP iniciou uma grande campanha de mídia estimulando que os brasileiros migrem as aplicações dos grandes bancos para empresas independentes de investimento com o objetivo de aumentar a rentabilidade das carteiras. Para Roberto Lee, diretor de marketing da XP, a "desbancarização" dos investimentos - ou seja, a troca de aplicações financeiras ruins e caras distribuídas pelos grandes bancos de varejo por bons produtos financeiros distribuídos por empresas independentes de investimento está longe de ser uma novidade. Nos anos 2000, os investidores trocaram os grandes bancos pelas corretoras independentes devido a funcionalidades e serviços como home broker que não sai do ar, relatórios de analistas, gráficos, notícias e assessoria de investimento. O que a XP deseja agora "é liderar o movimento de "desbancarização" de toda a carteira de investimentos", não apenas do movimento para a bolsa como anteriormente. (SANDRINI, 2015).

O carioca Guilherme Benchimol, da XP, de 36 anos, descobriu na prática como a educação é a base da prosperidade. Em 2002, ele e o sócio, o gaúcho Marcelo Maisonnave, de 37, perceberam que muitas pessoas deixavam de aplicar em ações por não entenderem como funciona o mercado financeiro (FRANÇA, 2013). No Brasil, a mais importante transação envolvendo um grande banco e uma corretora foi a da Ágora em 2008. Naquele o momento o Bradesco desembolsou 830 milhões de reais pela Corretora Ágora. Um valor correspondente a 10,53\% do Lucro do Banco em 2008 que havia sido de 7,2bi de reais. No momento daquela transação a Ágora lucrava 39 milhões de reais, assim a razão preço/lucro da transação era de 21,3 vezes. O preço de aquisição de cada cliente foi de 28,60 reais por cliente. (LAI e GALDI, 2017). 
Em 2016, Marcelo pôs fim a sua parte na sociedade e em 2017, um ano depois do fim do prazo previsto pela cláusula de não competição, Maisonnave está de volta ao mercado brasileiro com um negócio que promete simplificar a forma de se investir. Em parceria com outros executivos egressos da XP, o empresário lançou no Brasil o Warren, um sistema que faz a gestão de investimentos de forma automatizada. "Eu queria uma solução que pudesse atender gente como as amigas da minha mãe, que sempre me pediam ajuda para aplicar o dinheiro", brinca Maisonnave. Embora no mesmo segmento, a proposta de Maisonnave é diferente: Ao invés de produtos, "a gente vende um objetivo, uma gestão de uma carteira de investimentos" (LUZ, 2017). Ao longo dos anos, Benchimol desenvolveu um estilo peculiar de gestão. Ele mesmo se define como uma "pessoa intensa", algo que, para quem trabalhou com ele, transborda numa dificuldade de compartilhar decisões. "O Guilherme nasceu para ser dono, não para ser sócio", diz um ex-sócio (FILGUEIRAS, 2016).

Possui mais de 660 escritórios de agentes credenciados em 25 estados. 2 escritórios nos EUA e 2 na Europa. A propriedade do grupo XP é dividida entre a XP Controle, que detém a maior parte das ações, e a GA. Benchimol tentará equilibrar-se entre o que chama de "selo de qualidade" do Itaú e sua guerra aberta aos grandes bancos, que inclui roubar clientes do Itaú - cerca de $30 \%$ dos $\mathrm{R} \$ 5$ bilhões que a corretora capta por mês vêm de seu novo acionista. Segundo palavras dele, a operação se resume em ter "a liberdade de sempre" e "a chancela deles". (AGOSTINI, 2017).

Outras corretoras, como a Genial, do Banco Plural, e o BTG Pactual, têm campanhas publicitárias nacionais enaltecendo a independência e versatilidade na hora de aconselhar investimentos. (DYNIEWICZ, 2018). A partir de 2017, com a redução da taxa básica de juros brasileira (Selic), chegando em junho de 2018, a 6,75\% ao ano e em dezembro de 2019 a mínima histórica de 4,50\% ao ano - para atrair o investidor - a aposta é que as pessoas se abram mais a diferentes produtos de investimento dado que o retorno de aplicações conservadoras passe a encolher. Considerando a última década - 2009 a 2019 - aquele ganho numeroso de 14,25\% ao ano - de julho de 2015 até outubro de 2016 - acabou. 
Figura 1 Benchmarking corretoras.

\begin{tabular}{|c|c|c|c|c|}
\hline GENIAL INVESTIMENTOS & EASYNVEST & GUIDE INVESTIMENTOS & MIRAE ${ }^{(1)}$ & MODALMAIS \\
\hline $\begin{array}{l}\text { Fundação:2015. Uniãa entre } \\
\text { a corretora Geração Futuro } \\
\text { e a gestora Plural Capital }\end{array}$ & $\begin{array}{l}\text { Fundação: } 1968 \text {,como } \\
\text { Títula Corretora. Fol } \\
\text { repaginada em } 2014\end{array}$ & $\begin{array}{l}\text { Fundação: } 1967, \text { como } \\
\text { a corretora Indusval.Foi } \\
\text { reformulada em } 2013\end{array}$ & $\begin{array}{l}\text { Fundação: } 1997 . \\
\text { A corratora sul-coreana } \\
\text { chegau ao Brasillem } 2010\end{array}$ & $\begin{array}{l}\text { Fundação: } 1995 \text {, como } \\
\text { uma corretara tradicianal. } \\
\text { Foi reformulada em } 2014\end{array}$ \\
\hline $\begin{array}{l}\text { O que ofere-ce: } \\
\text { assessoria financeira e } \\
\text { Investimentos em fundos, } \\
\text { açōes e renda fixa }\end{array}$ & $\begin{array}{l}\text { O que oferece: } \\
\text { investimentos em açōes, } \\
\text { fundas e títulas derenda } \\
\text { fixa, camo CDBs }\end{array}$ & $\begin{array}{l}0 \text { que ofer ece: } \\
\text { assessorla financeira eq } \\
\text { investimentos em fundos, } \\
\text { açōes e renda fixa }\end{array}$ & $\begin{array}{l}\text { O que oferece: } \\
\text { títulos de renda fixa, } \\
\text { fundos de investimento, } \\
\text { aç̄̄es eopçত̃es }\end{array}$ & $\begin{array}{l}0 \text { que ofer ece: fundos } \\
\text { de investimento do banco } \\
\text { Madal e de terceiros, ações } \\
\text { e titulos de renda fixa }\end{array}$ \\
\hline $\begin{array}{l}\text { Número } \\
\text { de clientes: }\end{array}$ & $\begin{array}{l}\text { Número } \\
\text { declientes: }\end{array}$ & $\begin{array}{l}\text { Número } \\
\text { de clientes: }\end{array}$ & $\begin{array}{lc}\text { Número } & 0 \\
\text { de clientes: } & 16000\end{array}$ & $\begin{array}{l}\text { Múmero } \\
\text { de clientes: }\end{array}$ \\
\hline $\begin{array}{l}\text { Investimentos } \\
\text { solb custódia (em/eais) }\end{array}$ & $\begin{array}{l}\text { Investimentos } \\
\text { sob custódia (emreais) }\end{array}$ & $\begin{array}{l}\text { Investimentos } \\
\text { sob custódia (em reais) }\end{array}$ & $\begin{array}{l}\text { Investimentos } \\
\text { sob custódia (em reais) }\end{array}$ & $\begin{array}{l}\text { Investimentos } \\
\text { sob custódia (emseais) }\end{array}$ \\
\hline$\square 20$ bilhões & $\square 15$ bilhōes & 口 13 bilhões & $\square 10$ bilhōes & $\square 4$ bilhōes \\
\hline
\end{tabular}

Fonte: Bertão (2018).

A compra da XP pelo Itaú Unibanco despertou como nunca o interesse de dezenas de concorrentes do mercado de investimentos, a alcançar o volume de negócios da XP além de aportes bilionários. A XP, no ano da venda ao Itaú, possuía quinze anos de experiência no mercado, 450 mil clientes ativos e 90 bilhões de reais sob custódia (WEBSITE XP INVESTIMENTOS, 2017).

Em abril de 2016, o fundo de private equity General Atlantic (GA), sediado em Nova lorque ampliou sua participação (de $20,50 \%$ para $49 \%$ ) na XP com a compra da parte de propriedade do fundo inglês Actis. A GA entrou na sociedade da XP em 2012 (ALVES, 2016). A evolução das participações societárias da XP pode ser observada na Figura 2.

Figura 2 Linha do tempo XP Investimentos.

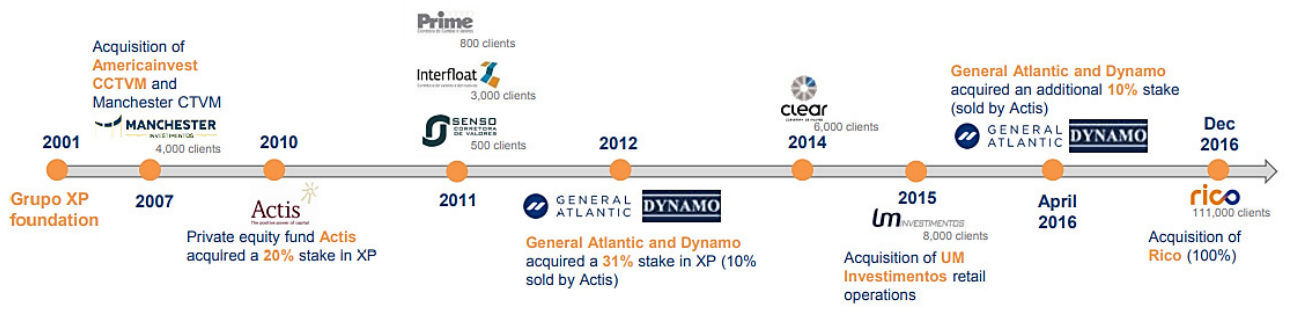

Fonte: Itaú Unibanco (2017). 
O presidente do Itaú Unibanco, Candido Bracher, chamou de inovadora a atuação da XP no mercado de distribuição de investimentos e gestão de recursos de terceiros. Para ele, é hora de possibilitar que os acionistas também participassem do crescimento dessa plataforma (ITAÚ, UNIBANCO, 2017). Bracher também procura, com a conclusão da compra da participação na XP, garantir que permaneça a independência de gestão. A contribuição do banco é no crescimento da empresa e geração de valor para o acionista (EQUIPE INFOMONEY, 2017).

Do ponto de vista do maior banco do Brasil, o histórico das fusões e aquisições realizadas (Figura 3) mostra que o Itaú Unibanco adiciona novas ideias aos poucos. Em 1995, comprou o BFB (Banco Francês e Brasileiro). Em 2002, comprou o BBA, reforçando sua área de investimentos, tornando real a criação do Itaú BBA. Em 2008, o Itaú adquiriu o Unibanco e, em 2010, a Redecard. Para a Consultoria Independente WhatsCall, a decisão do Itaú de comprar o Unibanco, foi marcada pela impossibilidade de replicar o modelo de negócio em um espaço de tempo adequado, de forma mais barata (KAHIL, 2017).

Figura 3 As mais relevantes fusões e aquisições do Itaú na era Roberto Setubal (1994-2016).

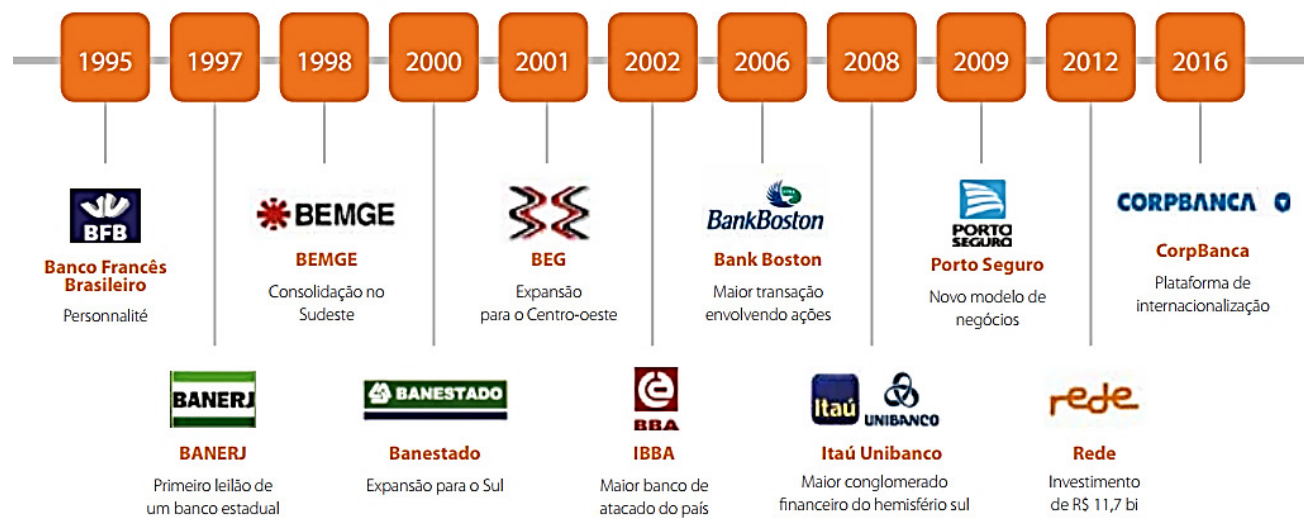

Fonte: Itaú Unibanco (2017). 


\section{A Transação}

Um total de 239 sócios e associados da XP venderam $37,4 \%$ de suas ações para o Itaú, embolsando em conjunto cerca de $\mathrm{R} \$ 2,26$ bilhões. Todos eles fazem parte da XP Controle, a holding dos sócios pessoa física da empresa e que representa a "partnership" (sociedade). A maioria dos 239 nomes da lista são associados, que possuem uma fração do capital. De qualquer forma, em muitos casos, a operação colocará alguns milhões no bolso dos executivos. A venda ao Itaú potencializou a geração imediata de riqueza, quando comparada ao efeito que teria a oferta inicial de ações. (ADACHI; MANDL, 2017).

Figura 4 Antes e depois da participação capital.
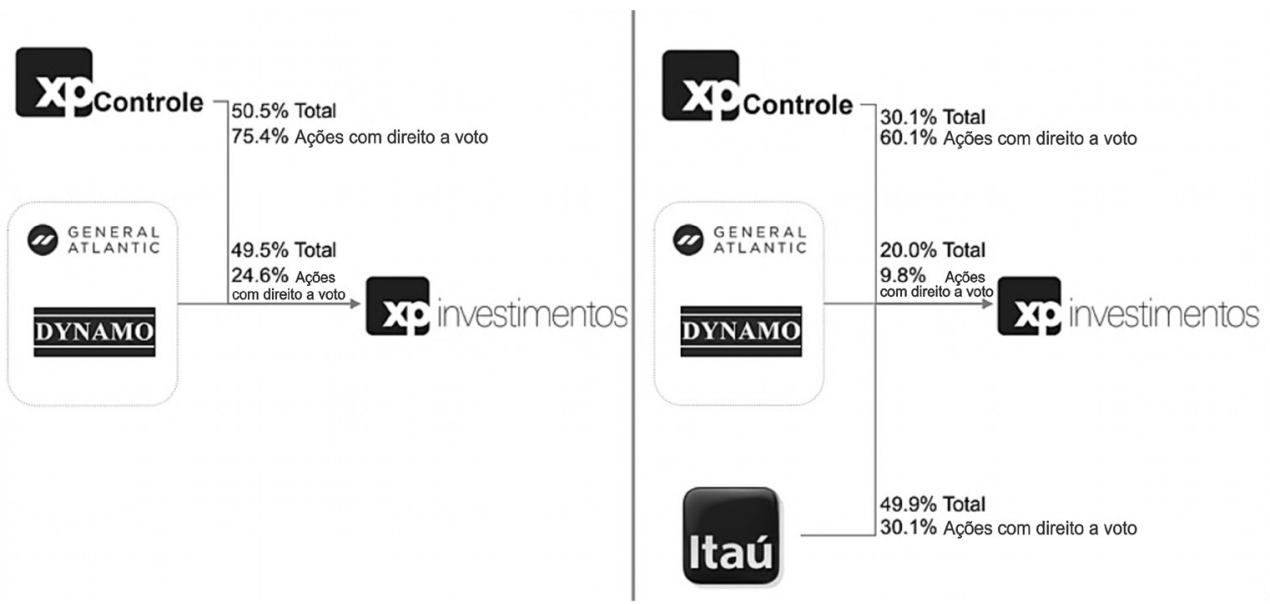

Fonte: Itaú Unibanco (2017).

Em teoria, o Itaú Unibanco torna-se apenas um acionista minoritário da XP Investimentos, sem ingerência na condução do dia-a-dia dos negócios. Nesse contexto, a operação não geraria vantagens diretas para o investidor, na medida em que ele poderia continuar se utilizando da XP normalmente, no mesmo modelo atualmente disponível (CALAZANS, 2017).

Entretanto, no momento do anúncio oficial da compra, o banco sinalizou que tem o propósito de adquirir o controle da XP ao passo que o acordo permitir. Isso 
pode ocorrer, inicialmente em 2020 , com compra adicional de mais $12,50 \%$ do capital social (sem direito a voto), e chegando a $74,90 \%$ do capital social total da XP em 2022. Em 2024, a XP poderia de fato exercer o poder de venda de $100 \%$ da empresa para o Itaú e, em 2033, o Itaú teria o direito de efetuar a compra de 100\% da XP. (LIS, 2018).

Figura 5 Cronograma da aquisição.

\begin{tabular}{|c|c|c|}
\hline Ano & Movimento & $\begin{array}{c}\% \text { do Itaú } \\
\text { Unibanco na XP }\end{array}$ \\
\hline 2017 & $\begin{array}{l}\text { Itaú Unibanco compra } 49,9 \% \text { do capital } \\
\text { total da XP. }\end{array}$ & 49,9 \\
\hline 2020 & Opção de compra do Itaú, de mais $12,5 \%$. & 62,4 \\
\hline 2022 & Nova aquisição, pelo banco, de $12,5 \%$. & 74,9 \\
\hline $\begin{array}{c}2024 \text { ou } \\
2033\end{array}$ & $\begin{array}{l}\text { A XP pode optar por vender os } 25,1 \% \\
\text { restantes. E o Itaú poderá exercer a opção } \\
\text { de compra da \% restante. }\end{array}$ & 100 \\
\hline
\end{tabular}

Fonte: Elaborado pelos autores, com base em Gradilone e Galembeck (2017).

A XP controlou entre 40 e 50 por cento dos volumes de transações entre as plataformas de investimento aberto no ano de 2017 (FEDEROWSKI; GOY, 2018). Benchimol retribui também o que Bracher vislumbrou com a parceria entre os dois gigantes. Para o fundador da XP, a inclusão do banco no quadro societário, traz ainda mais credibilidade e solidez. Ainda, torna-se uma plataforma para que a XP se torne a maior e melhor empresa de investimentos do Brasil (EQUIPE INFOMONEY, 2017). Com o planejamento de abrir seu capital em 2017 , até com a apresentação de um prospecto aos reguladores brasileiros de valores mobiliários no início desta semana, alguns dos clientes da empresa podem mesmo ter preferido que a empresa fosse pública. Há muito tempo que a XP se considera a alternativa aos bancos, e até usou uma campanha publicitária "anti-banking" agressiva para conquistar clientes em meados de 2015 e 2016, como um comercial que exortava as pessoas a "desbancarizar seus investimentos", como exemplo o vídeo "A Fuga dos Bancos" (CANAL XP INVESTIMENTOS, 2015). 
Se por um lado, a XP gostaria de passar uma imagem de que seguiria um modelo fora dos padrões dos bancos tradicionais, o Itaú a adquiria pela "simples" oportunidade de frear este driver de um modelo disruptivo de inovação tecnológica do mercado financeiro. Como uma governança hierárquica, as partes se integram para formar uma única entidade legal com propriedade unificada de ativos. O agora proprietário unificado, Itaú Unibanco, absorve o risco do ativo associado à transação por meio de contratos simples com prazo indeterminado (por exemplo, da propriedade e dos empregos). Esta nova configuração - passando de concorrente para sua subsidiária - proporciona uma distribuição relativamente mais segura do risco e uma estrutura contratual que é simples e transparente o suficiente para aliviar as restrições associadas ao nível de contratação das partes.

Além disso, em 11 de outubro de 2019, o Banco Central concedeu autorização para a XP atuar como banco. Sim, isso mesmo que você leu. O Banco XP poderá atuar com as carteiras comercial e de investimento e está autorizado a realizar operações no mercado de câmbio. A XP não somente deixou de lado a "desbancarização" como, agora que de fato faz parte de um modelo de bancos tradicionais, quer participar dessa competição. Deseja, "oferecer [...] o crédito mais barato do Brasil, sem nenhuma "taxinha", com uma experiência integrada com os meios de pagamentos e todos os seus investimentos de um jeito extraordinário" (EQUIPE INFOMONEY, 2019).

Guilherme Benchimol, presidente e fundador da XP Investimentos, foi um funcionário da antiga Investshop, o supermercado financeiro que o Unibanco comprou nos anos 90 e que teve as atividades encerradas depois da compra do banco dos Moreira Salles pelo Itaú, que não queria oferecer a seus clientes produtos de investimento concorrentes aos seus. O destino quis que esse mesmo Itaú agora enxergasse um valor bilionário no negócio criado por Benchimol e alguns sócios em 2001, inspirado justamente no que foi o Investshop. A transação faz de Benchimol o mais novo bilionário do Brasil. Como o Itaú avaliou a XP em R 12 bilhões antes do aumento de capital, sua fatia acionária de 22,5\% automaticamente vale $R \$ 2,7$ bilhões hoje (ADACHI; MANDL, 2017).

Para a conselheira do CADE, Cristiane Alkmin, "a XP incomoda o Itaú, não só pela sua base atual, mas por conta do potencial de clientes. Bancos como Itaú, 
com estruturas engessadas, teriam dificuldade para criar uma base de clientes como a da XP" (TOLEDO, 2018). Da mesma opinião dos dois conselheiros, é o ex-presidente do Banco Central, Armínio Fraga. Ele foi conselheiro do Itaú por cinco anos e é amigo dos controladores do banco. Para ele, o país precisa de mais concorrência, e o que a XP havia conquistado era o começo desta briga. "A questão mais relevante[...] tem a ver com o sucesso da XP em desenvolver uma base de clientes, a partir da qual se pode concorrer com os grandes bancos". A $\mathrm{XP}$, em um modelo de plataforma remota, despertou esse interesse todo do Itaú (SAFATLE, 2018).

Figura 6 Racionalidade da operação.

Do ponto de vista da XP

A XP deseja seguir sendo a líder no mercado de plataforma aberta, considerando que detém hoje cerca de $50 \%$ deste mercado, seguida de longe pela Planner que possui entre $9 \%$ e $13 \%$. Embora o plano inicial possa ter sido um IPO, optou por vender $75 \%$ para o Itaú e ter saída definitiva até 2033.

\section{Do ponto de vista do Itaú}

O Itaú, assim como todos os bancos de varejo, tem perdido clientes principalmente para a XP. A estratégia Itaú é a de minimizar as suas perdas decorrentes desse novo modelo de investimento, comprando a empresa que mais tem drenado seus clientes (e funcionários!). Com a operação o Itaú passaria a ter uma perda menor, podendo representar a "recompra" dos clientes perdidos pelo Itaú para a XP, incluindo a "compra" daqueles que eram só da XP e a "recompra" de todos os clientes que poderiam no futuro migrar para lá.

Fonte: CADE (2018).

\section{Desdobramentos}

Mas então, qual o benefício para a XP e para o Itaú Unibanco, na transação de aquisição? A XP não preza mais pela "desbancarização"? 
Com o passo dado pelo Itaú "acreditamos que a decisão de comprar a concorrente foi pautada na falta da possibilidade de replicá-la em tempo hábil, de uma forma mais barata e eficiente", ressalta a consultoria WhatsCall, que calcula o preço adquirido por cliente em torno de 52 mil reais (EQUIPE MONEY TIMES, 2017). No dia 27 de dezembro de 2017, a Superintendência Geral do Conselho Administrativo de Defesa Econômica (CADE) decidiu, recomendar o acordo entre XP Investimentos e o Itaú Unibanco, condicionada à celebração do acordo em controle de concentrações proposto pelo CADE (FEDEROWSKI; GOY, 2018), pois envolve o maior banco privado país e a maior corretora e distribuidora de investimentos (WIZIACK; CARNEIRO, 2018).

Após o parecer, na quarta-feira 18 de março de 2018, o CADE aprovou por 5 votos a 2 acordo entre a corretora XP Investimentos e Itaú Unibanco. Entre as principais exigências, está a de que o Itaú se comprometa a não discriminar plataformas concorrentes da XP, também que a corretora continua independente e com autonomia na sua gestão (FEDEROWSKI; GOY, 2018). O parecer do acordo afirma que "entende-se que dado o contexto da operação, o ACC negociado (acordo proposto entre Itaú Unibanco e CADE) é suficiente para afastar as preocupações concorrenciais" (DANTAS, 2017). O acordo tem validade até 31 de dezembro de 2022 (WIZIACK; CARNEIRO, 2018).

A transação, ainda estaria sujeita à aprovação do Banco Central. E aconteceu. Em 10 de agosto de 2018, o Banco Central emitiu a aprovação da compra, restringindo a parte do Itaú Unibanco. $O$ banco não poderá ter o controle da XP até 2026. Além desta restrição, o Banco se comprometeu a não indicar executivos para as áreas financeira e de operações, nem ter acesso durante 15 anos da base de clientes e de prestadores de serviço da XP. (NAPOLITANO, 2018). Mas a discussão neste caso é sobre as estratégias na tomada de decisão de compra e venda. Benchimol traçou estratégia para crescer $700 \%$ em apenas três anos - atingindo a marca de 4 mil clientes - e passar de $R \$ 126$ bilhões sob custódia para a marca de $\mathrm{R} \$ 1$ trilhão. Empresa conta hoje com 1,1 mil pessoas em sua equipe e alcançara 1,5 mil até dezembro. Em 2017, cresceu 92\%. A corretora vai transferir, em maio, seu escritório para um espaço de 12 mil metros quadrados, mais do que o dobro do atual (DYNIEWICZ, 2018).

Por outro lado, "nem tudo são flores". Para Luis Miguel Santacreu, da Austin Rating, uma agência classificadora de risco brasileira, o avanço de outras correto- 
ras independentes também pode prejudicar o projeto da XP. "O modelo dela está sendo copiado. Antes, ela nadava sozinha. A XP tem crescido a uma taxa favorável, mas perpetuar isso é bem otimista." (DYNIEWICZ, 2018). O projeto de Benchimol é bastante "audacioso", mas não o considera impossível. "As taxas de juros são favoráveis, mas dependerá de quanto o mercado como um todo conseguirá crescer", comentou o diretor de inovação da consultoria Accenture, Guilherme Horn (DYNIEWICZ, 2018).

Desta forma, qual a lógica por trás da aquisição da XP pelo Itaú Unibanco? Não seria capaz o maior banco do Brasil, de desenvolver tais capacidades adquiridas da corretora? As capacidades internalizadas da XP são tão valiosas?

\section{Notas de Ensino}

\section{FONTES DE DADOS}

O caso para ensino foi construído com fontes de dados de origem secundária. A construção do enredo histórico da empresa e a descrição das pessoas envolvidas no caso foram obtidas por meio de matérias de revistas de circulação nacional, revistas digitais, páginas da internet e website das respectivas companhias que compõem o caso.

Os dados e informações apresentadas na parte da história do caso são reais. A coleta se deu por meio de reportagens em revistas, páginas da internet, políticas, estatutos e regimentos das companhias. São exemplos disso: Folha de São Paulo, Revista Exame, Revista Isto é Dinheiro, Revista VEJA, Valor Econômico, Estadão e Reuters. Portanto, trata-se de uma situação-problema real vivida por protagonistas reais, inclusive a redação possui suporte em documentos públicos de órgãos do governo, atores da referida transação.

\section{OBJETIVOS DIDÁTICOS}

- Proporcionar o conhecimento acerca da estrutura de governança e da teoria dos custos de transação à luz da operação de aquisição parcial da XP Investimentos por parte do Itaú Unibanco, no cenário de inovação tecnológica do mercado financeiro brasileiro. 
- Desenvolver uma visão crítica para tomar decisão - a compra das operações de corretagem - especialmente, na dificuldade de se desenvolver internamente pela alta especificidade do ativo.

- Compreender o cenário econômico ilustrado, com base na atual migração para inovação tecnológica e ambiente de "desbancarização".

\section{UTILIZAÇÃO DO CASO}

Este caso para ensino pode ser utilizado para discussão em cursos de graduação, MBA, mestrado e doutorado, tanto acadêmico como profissional, em Administração e Gestão, especialmente em disciplinas relacionadas a finanças, mercado de capitais e estratégia.

Os alunos são convidados a ficar no lugar, por um lado, da empresa XP, que vendeu $49,9 \%$ de seu capital social, e por outro lado, do Itaú Unibanco, comprador desta fatia. Recomendamos que, antes de se iniciar a Etapa 3 (Figura 7) seja realizada a leitura das fontes de dados na íntegra e das obras em referências.

Figura 7 Plano de aula sugerido.

\begin{tabular}{|c|c|c|c|}
\hline Etapa & $\begin{array}{l}\text { Tempo } \\
\text { Estimado }\end{array}$ & Atividade & $\begin{array}{l}\text { Conceitos } \\
\text { Mobilizados }\end{array}$ \\
\hline 1 & $0-15 \min$ & $\begin{array}{l}\text { Apresentação do caso e exposição dos } \\
\text { objetivos }\end{array}$ & Objetivos \\
\hline 2 & $15-20 \mathrm{~min}$ & $\begin{array}{l}\text { Seminário para argumentação das motiva- } \\
\text { ções do caso e resultados esperados com o } \\
\text { objetivo proposto pelo caso. }\end{array}$ & Contexto \\
\hline 3 & $90-120 \mathrm{~min}$ & $\begin{array}{l}\text { Dividir a sala em dois grupos (plenário). Uma } \\
\text { metade da classe fica responsável por res- } \\
\text { ponder de forma favorável a todas as ques- } \\
\text { tões, e a outra, defende de forma contrária. }\end{array}$ & $\begin{array}{l}\text { Estrutura de gover- } \\
\text { nança } \\
\text { Teoria dos custos } \\
\text { de transação }\end{array}$ \\
\hline 4 & $20-40 \mathrm{~min}$ & $\begin{array}{l}\text { Fechamento da aula com relato das toma- } \\
\text { das de decisão a partir de então e possíveis } \\
\text { desfechos alternativos. }\end{array}$ & $\begin{array}{l}\text { Decisões das com- } \\
\text { panhias perante o } \\
\text { caso, a curto, médio } \\
\text { e longo prazo }\end{array}$ \\
\hline
\end{tabular}

Fonte: Elaborado pelos autores. 
De maneira alternativa, sugerimos também que as questões recomendadas sejam preparadas em pequenos grupos (assignment questions) diferentes das questões que pautam a discussão em plenário (discussion questions). Esta forma de preparação em pequenos grupos deve servir para aprofundar o entendimento dos participantes sobre o caso sem antecipar a articulação do caso com a teoria. Espera-se que a articulação do caso com a teoria seja facilitada pelo professor no momento da discussão, onde também, neste momento, debate-se a questão específica: Não seria capaz o maior banco do Brasil, de desenvolver tais capacidades adquiridas da corretora? As capacidades internalizadas da XP são tão valiosas?

Por fim, sugerimos ainda que o professor apresente questões de transição (transition questions), isto é, em meio as questões propostas, discutir questões da atualidade, trazendo para o momento atual o que aconteceu no caso ou até mesmo comparando com outros casos de aquisição de fintechs e pequenos bancos pelos grandes players de mercado.

\section{QUESTÕES PROPOSTAS PARA DISCUSSÃO}

Nesta seção, apresentamos questões que podem ser utilizadas, seguindo os objetivos educacionais, para discutir os temas da estrutura de governança e a teoria dos custos de transação.

1. O que a XP Investimentos apresentava de tão importante para que o Itaú Unibanco tenha tomado a decisão de adquirir a corretora? Cite os diferenciais e características que os diretores do banco enxergaram.

2. Sabendo da decisão do Itaú Unibanco de internalizar a atividade de corretagem de valores, via hierarquia, justifique esta decisão.

3. Quais os benefícios diretos do Itaú Unibanco ao comprar a XP Investimentos, uma corretora de valores?

4. Qual o interesse principal na aquisição para o Itaú? E para a XP?

\section{SUGESTÃO DE ENCAMINHAMENTO PARA AS QUESTÕES PROPOSTAS}

\section{Questão 1.}

O artigo de Ronald Coase (1937) foi o pioneiro no estudo dos custos de transação, reconhecendo sua existência para um nível além dos custos de produção 
- da economia industrial. A visão de Coase foi aprofundada em trabalhos posteriores (WILLIAMSON, 1981; 1991). Williamson (1981) entende que uma transação é a transferência de um bem ou serviço de uma atividade para outra, balizadas por uma base tecnológica separada.

Na prática, para Coase (1937), em determinado momento há uma igualdade do custo de se realizar transações via mercado e realizar internamente. Isto se dá, à medida que tamanho da empresa cresce. A decisão entre internalizar e realizar a mercado está relacionada aos custos de transação envolvidos na especificidade dos ativos. Também na quantidade de valor que se perde quando se utiliza um ativo em atividade que ele não é específico.

Especificamente para o caso aqui exposto, o Itaú abocanha uma carteira de clientes que a XP construiu tirando clientes dos demais bancos. Logo, estaria ele resgatando clientes de todos os bancos que acabou o próprio Itaú falhando na retenção destes, bem como, os próprios que a XP atraiu. O caso XP e Itaú ainda lembra a General Motors dos EUA, durante a década 20, quando percebeu que os bondes elétricos que transportavam 9 em cada 10 viagens nos EUA eram uma ameaça ao negócio automobilístico. A solução encontrada pelo presidente da GM, Alfred $P$. Sloan Jr., foi se juntar com outros interessados na questão como a fabricante de pneus Goodyear, Firestone e as petrolíferas, como a Standard Oil, para comprar diversas empresas de bondes elétricos nos EUA, fechá-las, e assim simplesmente eliminar a competição (LAl; GALDI, 2017).

Para Williamson (1981) a alta performance econômica seria obtida pela capacidade de adaptar as atividades da empresa eficientemente, contornando a incerteza. A incerteza é um risco não calculado, difícil de se prever. Por consequência, as transações tornam-se mais custosas. Assim, dentro do entendimento que a organização por si só é complexa e que os agentes envolvidos nas transações possuem limitações cognitivas, entende-se que a troca econômica deve ser mediada por um contrato.

\section{Questão 2.}

A estrutura de governança é a unidade onde residem os custos de transação representados pela hierarquia (WILLIAMSON, 1981) (quando a especificidade dos ativos é alta e a firma opta por sua produção ao invés de compra). A eco- 
nomia dos custos de transação sustenta que economizar custos de transação é o processo principal de pensar um meio pelo qual a economizar em racionalidade limitada e mitigar os riscos que se acumulam ao oportunismo. E a governança é um meio pelo qual para gerar ordem em uma relação onde o potencial de conflito ameaça desfazer ou oportunidades variadas para realizar ganhos mútuos. (WILLIAMSON, 1999).

Três tributos básicos definem a transação: i) frequência, ii) incerteza e iii) especificidade dos ativos envolvidos. A especificidade dos ativos, é o principal elemento, aquele que irá determinar se a atividade será exigida a mercado ou realizada pela firma. À medida que os recursos se tornam cada vez mais especializados, a escolha econômica da governança passa de mercados para híbridos e hierarquias (ARGYRES; MAHONEY; NICKERSON, 2019), com contratos de longo prazo. O inverso é quando ativos de menor especificidade, podem ser gerenciados a mercado. A teoria dos custos de transação conecta a proteção do comportamento oportunista à adoção de mecanismos de governança, por isso, quanto maior a especificidade dos ativos - maior a chance de comportamento oportunista - mais próxima a forma de governança está da integralização, também chamada de verticalização (RODRíGUEZ-LOPES; DIZ-COMESAÑA, 2016). O propósito das escolhas, para um lado, ou outro também é, reduzir os custos de transação através da eficiência, visando alcançar vantagens competitivas sustentáveis. Ainda, pode ocorrer a elaboração de contratos incompletos e riscos durante a negociação. Por isso, neste caso, optando pelo sistema de hierarquia, internalizando as transações, a empresa precisa obter uma estrutura organizacional eficiente, que reduze custos de governança e produção (WILLIAMSON, 1981).

Entre as duas estruturas indicadas acima - mercado e hierarquia - existem as estruturas híbridas, basicamente realizando-se via contratos de longo prazo. Em suma, o custo de realizar as transações atinge um nível tão alto, que a organização prefere internalizar a transação e realizar por si própria, inclusive por vezes obtendo resultados melhores do que quando realizado a mercado. A Figura 8 resume as três formas da estrutura de governança debatidas. 
Figura 8 Respostas organizacionais para a incerteza.

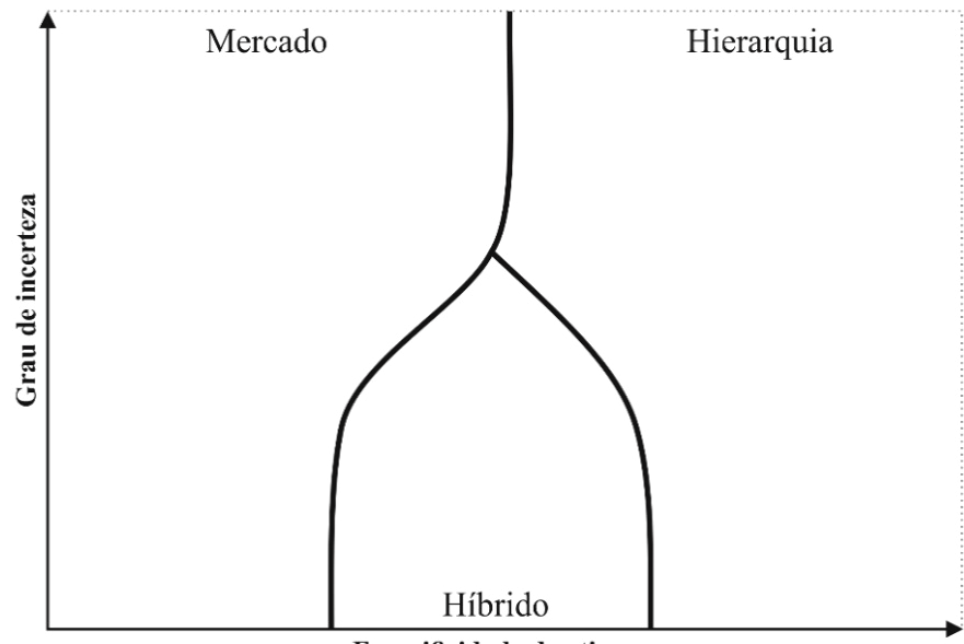

Especificidade de ativos

Fonte: Elaborado com base em Williamson (1991).

A hierarquia e/ou autoridade existem para delimitar o limite do empregado com o poder do empregador, por consequência evitar o oportunismo. A estrutura de governança escolhida pelas empresas é definida com base nas condições de preço e tecnologia. Deste modo, a estrutura de governança da especificidade de ativos a mercado é favorável devido a mínima quantidade de ativo específico entre as partes. Por outro lado, estruturas hierárquicas são favoráveis para o uso quando há alta especificidade de ativos. (WILLIAMSON, 1981).

Por fim, falhas de mercado (oportunismo e racionalidade limitada) associadas a informações completas e assimétricas, e também a mercados imperfeitos, são aspectos que afetam os custos de transação, neste sentido, uma empresa pode decidir sobre o nível de internalização dos processos produtivos, uma maneira de estabelecer sua "estrutura de governança” (PEREIRA; LOPES, 2018).

\section{Questão 3.}

A compra da XP pelo Itaú, em partes, foi baseada na ameaça de que a "desbancarização", isto é, que as transações financeiras ocorrerão cada vez mais fora do sistema bancário, o que poderia ser a grande próxima tendência do setor finan- 
ceiro, e com isso os negócios do banco pudessem ser duramente penalizados. Talvez não acreditasse tanto na tese da "desbancarização". A XP percebeu que é bom oferecer uma grade completa de serviços bancários do que apenas serviços de corretagem (LAl; GALDI, 2017).

Nem todas as empresas podem ser igualmente competentes na implantação de suas capacidades institucionais para proteger os seus conhecimentos. Para a teoria da economia dos custos de transação, os agentes econômicos são capazes de olhar em frente e reconhecer os riscos contratuais e oportunidades de investimento (WILLIAMSON, 1999).

Até antes dos estudos iniciais de Coase, prevalecia o sistema de preço, que regulava a produção e o consumo de mercadorias pela determinação de valor, na concepção de que: o preço refletia tudo. Porém, o ponto falho é que, quando se define o preço, o comprador e vendedor não tem informação definida. Se a empresa terceirizar, ela vai perder aquilo que ela tinha internalizado, e poderia ser uma vantagem competitiva dela além de uma barreira de mercado para aquela tecnologia ou recurso.

Por outro ponto de vista - da racionalidade e hierarquia limitadas - estruturas de governança com propriedade unificada de ativos podem surgir como uma resposta às capacidades de contratação assimétricas e à incapacidade de uma parte mais fraca de proteger seus interesses nas negociações. Esse argumento vai ao encontro de pesquisas que sugerem que os atores dentro e fora das empresas se organizam para mitigar custos de transação limitados baseados em racionalidade (FOSS; WEBER, 2016).

Além disso, o desejo de passar rapidamente para uma nova posição de mercado pode causar um aumento nos custos de transação. Esse custo adicional pode vir a ser compensado por vantagens que resultam em um reposicionamento mais rápido - como a compra de um grande concorrente, ou da vantagem do pioneiro (ARGYRES; MAHONEY; NICKERSON, 2019).

As instituições existem para reduzir os custos de transação, aumentar volume e criar valor. Aquelas que se formam em estilos "piramidais", diversificam suas atividades com outras empresas subsidiárias, são exemplos, além do caso exposto, a Gerdau e a Votorantim. Em um exemplo prático: eu crio o meu próprio banco, pra eu gerar valor e lucro, e evito a expropriação de valor das instituições para mim. 
Outro exemplo são os business groups, os quais são formados para dar resposta aos custos de transação.

\section{Questão 4.}

Empresas que aumentam de tamanho ao longo da trajetória de vida, enfrentam maiores dificuldades (custo de transação) para coordenar as atividades que estão mais distantes de sua planta. Por outro lado, as inovações, tal como melhorias nas comunicações, permitem reduzir esses custos de gerenciamento deste distanciamento e desse modo, permitem que a empresa continuamente avance com seus projetos de expansão. (COASE, 1937).

O interesse por trás da grande operação de aquisição é, especialmente, para o Itaú: ganha o acesso aos 2 mil assessores de investimentos em mais de 660 escritórios credenciados pela corretora. Além disso, o controle da XP pode passar na integridade para o Itaú. Em 2024, a XP pode exercer a venda, na totalidade, de sua participação na corretora. Caso não ocorra, em 2033, o Itaú poderá comprar todas as ações da XP (KAHIL, 2017).

Já para a XP: é estratégico, vai matar a concorrência. Embora, o Bradesco, supostamente, também mataria a concorrência ao comprar a Ágora, à época, a Ágora era bem maior que a XP. Se você tira um concorrente do jogo, outro nasce no lugar se, de fato, existe um espaço de mercado a ser preenchido", afirma Felipe Miranda, estrategista-chefe da Empiricus Research (KAHIL, 2017). A estratégia da XP foi perfeita. A compra pelo Itaú mostra o quanto um marketing coerente e agressivo pode assustar até mesmo um gigante financeiro do porte do Itaú, o que faz lembrar um ditado alemão: O medo faz o lobo parecer ser maior do que ele realmente é (LAl; GALDI, 2017). Embora algumas corretoras tenham aprimorado seus programas de educação financeiras, estas instituições não são um símbolo de solidez para os investidores. Os bancos tradicionais ainda representam uma imagem de segurança e confiança. A transação também ocorre com esta prerrogativa, dado que, a XP se unindo em parceria com o Itaú, leva de "bandeja" a imagem e solidez do grande banco.

\section{ENCERRAMENTO DA DISCUSSÃO DO CASO}

Como sugestão para o encerramento da discussão do caso, tem-se a proposição de uma situação desafiadora. Trazer em plenário as demais fusões e aqui- 
sições ocorridas no cenário brasileiro nos últimos cinco anos, no setor. Também, filtrando pelas que mais repercutiram na história, fazendo uma análise do ponto de vista, das empresas adquirentes ou que se fundiram, sobre suas tomadas de decisão destes atos. Ainda, levantar os novos tratamentos dados e estratégias geradas, com a abertura do capital da XP na bolsa de valores americana (NASDAQ). Também, seja se o banco não houvesse realizado a compra, ou tivesse recuado após algum dos entraves entre CADE e Banco Central, será que a XP, teria concluído a sua intenção de realização do IPO na bolsa de valores brasileira (B3)? Haveria outro concorrente interessado na sua aquisição?

Em um caso para ensino não há respostas únicas corretas, mas sim, as respostas mais adequadas que podem levar a uma melhor decisão. Certamente, o encerramento do caso com uma situação nova e desafiadora instigará os alunos a pensarem mais sobre o tema fora da sala de aula.

\section{Referências}

ADACHI, V.; MANDL, C. Venda de ações para Itaú cria novos milionários na XP. Valor Econômico, 15 maio 2017. Disponível em: <https://valor.globo.com/financas/noticia/2017/05/15/venda-de-acoes-para-itau-cria-novos-milionarios-na-xp-1.ghtml>. Acesso em: 3 out. 2019.

AGOSTINI, R. Após comprar participação, Itaú acelera meta de crescimento da XP. Folha de São Paulo, 16 maio 2017. Disponível em: <https://www1.folha.uol.com.br/mercado/2017/05/1884357-apos-comprar-participacao-itau-acelera-meta-de-crescimento-da-xp.shtml>. Acesso em: 15 jun. 2019.

ALVES, A. Com R $\$ 450$ milhões, General Atlantic amplia fatia na XP Investimentos para 49\%. Reuters, 14 abr. 2016. Disponível em: < https://br.reuters.com/article/idBRKCNOXB2TS>. Acesso em: 8 jun. 2019.

Após admitir conversas com Itaú Unibanco, XP Investimentos pede registro para IPO. Reuters, 10 maio 2017. Disponível em: <https://br.reuters.com/article/topNews/idBRKBN1862TW-OBRTP>. Acesso em: 21 jun. 2019.

ARGYRES, N.; MAHONEY, J. T.; NICKERSON, J. Strategic responses to shocks: Comparative adjustment costs, transaction costs, and opportunity costs. Strategic Management Journal, v. 40, p. 357-376, 2019. DOI: 10.1002/smj.2984

BERTÃO, N. A XP aponta o caminho para as corretoras. Revista Exame, v. 1166, n. 14, a. 52, p. 28-37, 25 jul. 2018.

CADE. Voto Vogal Conselheira Cristiane Alkmin Junqueira Schmidt. Ato de Concentração $n^{\circ}$ 08700.004431/2017-16, 19 mar. 2018. Disponível em: <https://sei.cade.gov.br/sei/modulos/pesquisa/md_pesq_documento_consulta_externa.php?DZ2uWeaYicbuRZEFhBt-n3BfPLlu9u7akQAh8mp- 
B9yO4010Julg1b1ljy5nQXmigasajw0F1yZwi9NpFATfICQMeEHdC64mpgFkuLeQkOCwzZv2NMZT1JJuMy70SmtZb>. Acesso em: 17 ago. 2019.

CALAZANS, B. XP e Itaú: como a fusão pode impactar o mercado. ADVFN News, 25 out. 2017. Disponível em: < https://br.advfn.com/jornal/2017/10/xp-e-itau-como-a-fusao-pode-impactar-o-mercado>. Acesso em: 26 out. 2019.

CANAL XP INVESTIMENTOS. A fuga dos bancos. Youtube, 1 dez. 2015. Disponível em: <https://www. youtube.com/watch?v=N_Y_GY82Vzg>. Acesso em: 9 abr. 2019.

COASE, R. H. The Nature of the Firm. Economica, v. 4, p. 386-405, 1937. DOI: 10.1111/j.1468-0335.1937. tb00002. $x$

DANTAS, I. Superintendência do Cade recomenda aprovação de acordo Itaú com XP Investimentos sob condições. Reuters, 27 dez. 2017. Disponível em: <https://br.reuters.com/article/topNews/idBRKBN1EL1R9-OBRTP>. Acesso em: 6 abr. 2019.

DYNIEWICZ, L. Com Itaú como sócio, XP quer superar bancos e virar líder em investimentos. Estadão, 19 fev. 2018. Disponível em: <https://economia.estadao.com.br/noticias/geral,com-itau-como-socio-xp-quer-superar-bancos-e-virar-lider-em-investimentos,70002194546>. Acesso em: 20 abr. 2019.

DYNIEWICZ, L.; LUZ, C. Proposta de venda do controle da XP não foi colocada na mesa. Estadão, 15 maio 2017. Disponível em: <https://economia.estadao.com.br/noticias/negocios,proposta-de-venda-do-controle-da-xp-nao-foi-colocada-na-mesa,70001781950>. Acesso em: 12 jul. 2019.

. Não estou alinhado a interesses do Itaú. Estadão, 15 maio 2017, Disponível em: <https://economia.estadao.com.br/noticias/negocios,nao-estou-alinhado-a-interesses-do-itau,70001781949>. Acesso em: 12 jul. 2019.

EQUIPE INFOMONEY. XP associa-se com Itaú e vende fatia minoritária por $\mathrm{R} \$ 6,3$ bi; veja íntegra do comunicado. Infomoney, 12 maio 2017. Disponível em: <https://www.infomoney.com.br/itauunibanco/ noticia/6456280/associa-com-itau-vende-fatia-minoritaria-por-veja-integra-comunicado>. Acesso em: 12 abr. 2019.

. Banco Central autoriza XP a operar como banco múltiplo. Infomoney, 12 out. 2019. Disponível em: < https://www.infomoney.com.br/mercados/banco-central-autoriza-xp-a-operar-como-banco-multiplo>. Acesso em: 03 abr. 2020.

EQUIPE MONEY TIMES. Por que o Itaú pagou R\$ 52 mil por cada cliente da XP?. Money Times, 12 maio 2017. Disponível em: < https://www.moneytimes.com.br/por-que-o-itau-pagou-r-52-mil-por-cadacliente-da-xp/>. Acesso em: 17 set. 2019.

FEDEROWKI, B.; GOY, L. Brazil watchdog approves Itaú-XP deal, no asset sales required. Reuters, 14 mar. 2018. Disponível em: < https://www.reuters.com/article/us-xp-investimentos-m-a-itau-unibcohldg/brazil-watchdog-approves-ita-xp-deal-no-asset-sales-required-idUSKCN1GQ2GE>. Acesso em: 19 jun. 2019.

FILGUEIRAS, M. L. Por que esta empresa incomoda tanto os grandes bancos?. Revista Exame, 12 set. 2016. Disponível em: < https://exame.abril.com.br/revista-exame/por-que-esta-empresa-incomoda-tanto-os-grandes-bancos/>. Acesso em: 12 out. 2019.

FOSS, N. J.; WEBER, L. Moving opportunism to the back seat: Bounded rationality, costly conflict, hierarchical forms. Academy of Management Review, 41: 61-79, 2016. DOI: 10.5465/amr.2014.0105 
FRANÇA, C. Guilherme Benchimol, o professor de finanças que criou a XP. Revista Exame, 29 out. 2013. Disponível em: <https://exame.abril.com.br/pme/guilherme-benchimo-o-professor-de-financas/>. Acesso em: 26 ago. 2019.

GRADILONE, C.; GALEMBECK, F. XP: Venda ao Itaú leva Guilherme Benchimol ao topo do mundo. Isto É Dinheiro, 12 maio 2017. Disponível em: <https://www.istoedinheiro.com.br/xp-venda-ao-itau-leva-guiIherme-benchimol-ao-topo-mundo/> Acesso em: 21 jul. 2019.

ITAÚ UNIBANCO. Presentation. Acquisition of a Minority Interest in XP Investimentos, 8 out. 2018. Disponivel em: <https://www.itau.com.br/relacoes-com-investidores/show.aspx?idCanal=xpXG5+IFd7echRmOaeYUcQ==\&linguagem=en>. Acesso em: 26 ago. 2019.

. Ações Itaú em foco, a. $14-1^{\circ}$ tri. 2017. Disponível em: <https://www.itau.com.br/relacoes-com-investidores/Download.aspx?Arquivo=qtfzMhy9CnBfUJvm/Q3V9A==>. Acesso em: 23 set. 2019.

KAHIL, G. Quem ganha com a Itaú e XP juntos? Empiricus e Eleven comentam impactos para o mercado e investidores. Money Times, 10 maio 2017. Disponível em: <https://www.moneytimes.com.br/quemganha-com-a-itau-e-xp-juntos-empiricus-e-eleven-comentam-impactos-para-o-mercado-e-investidores/>. Acesso em: 17 maio 2019.

. Por que o Itaú pagou R\$ 52 mil por cada cliente da XP?. Money Times, 12 maio 2017. Disponível em: < https://www.moneytimes.com.br/por-que-o-itau-pagou-r-52-mil-por-cada-cliente-da-xp/>. Acesso em: 13 jul. 2019.

LAI, S.; GALDI, P. Itaú e XP: o medo fez o lobo parecer maior do que era?. Upside Investor, 13 maio 2017. Disponível em: < http://www.upsideinvestor.com>. Acesso em: 3 abr. 2019.

LIS, L. Cade aprova compra de 49,9\% da XP Investimentos pelo Itaú. G1 Economia, 14 mar. 2018. Disponível em: <https://g1.globo.com/economia/noticia/cade-aprova-compra-de-499-da-xp-investimentos-pelo-itau.ghtml>. Acesso em: 8 abr. 2019.

LUZ, C. Ex-XP volta ao mercado com 'fintech' de investimento. Estadão, 13 abr. 2017. Disponível em: $<$ https://economia.estadao.com.br/noticias/geral,ex-xp-volta-ao-mercado-com-fintech-de-investimento,70001736979>. Acesso em: 11 jul. 2019.

NAPOLITANO, G. Banco Central autoriza compra da XP pelo Itaú, mas com restrições. Revista Exame, 10 ago. de 2018. Disponível em: < https://exame.abril.com.br/negocios/banco-central-autoriza-compra-da-xp-investimentos-pelo-itau-unibanco/> Acesso em: 9 abr. 2019.

NASCIMENTO, D. P. Stablecoins poderiam solucionar a desbancarização em economias emergentes? Money Times, 17 fev. 2020. Disponível em: <https://www.moneytimes.com.br/fast/stablecoins-poderiam-solucionar-a-desbancarizacao-em-economias-emergentes>. Acesso em: 05 abr. 2020.

OLD, D. Fintechs são novas portas de acesso a serviços financeiros. Revista Exame, 19 mar. 2019. Disponível em: <https://exame.abril.com.br/negocios/dino_old/fintechs-sao-novas-portas-de-acesso-a-servicos-financeiros>. Acesso em: 07 abr. 2020.

PASSARO, J. Itaú considera imposto sobre transações financeiras com "muitos problemas". Suno Research, 20 ago. 2019. Disponível em: <https://www.sunoresearch.com.br/noticias/itau-imposto-sobre-transacoes-financeiras-muitos-problemas>. Acesso em: 08 abr. 2020.

PEREIRA, A. J.; LOPES, H. C. The market for the "old" and the "new" institutional economics. Brazilian Journal of Political Economy, v. 38, n. 3, p. 450-468, 2018. DOI: 10.1590/0101-35172018-2774 
REDAÇÃO REVISTA VEJA. Itaú confirma interesse em comprar parte da XP Investimentos. Revista Veja, 10 maio 2017. Disponível em: <https://veja.abril.com.br/economia/itau-confirma-interesse-na-corretora-xp-investimentos/>. Acesso em: 9 abr. 2019.

RODRÍGUEZ-LOPES, N.; DIZ-COMESAÑA, M. E. The mediated effect of formal and informal control on governance forms. RAE-Revista de Administração de Empresas, v. 56, n. 6, p. 655-667, 2018.

SAFATLE, C. Para Arminio, Cade errou ao aprovar negócio entre XP e Itaú. Valor Econômico, 22 mar. 2018. Disponível em: <https://valor.globo.com/financas/coluna/para-arminio-cade-errou-ao-aprovar-negocio-entre-xp-e-itau.ghtml>. Acesso em: 9 abril 2019.

SAMOR, G. Itaú comprará 49,5\% da XP por R 6 bi, diz revista. Brazil Journal, 9 maio 2017. Disponível em: <https://braziljournal.com/itau-comprara-495-da-xp-por-r-6-bi-diz-revista> Acesso em: 12 jul. 2019. SANDRINI, J. 8 motivos para você "desbancarizar" seus investimentos, segundo a XP. Infomoney, 14 dez. 2015. Disponível em: <https://www.infomoney.com.br/onde-investir/8-motivos-para-voce-desbancarizar-seus-investimentos-segundo-a-xp>. Acesso em: 08 abr. 2020.

TOLEDO, L. A XP, o Itaú e o novo desafio do Cade: negócios inovadores. Revista Exame, 14 mar. 2018. Disponível em: <https://exame.abril.com.br/negocios/a-xp-o-itau-e-o-novo-desafio-do-cade-negocios-inovadores/>. Acesso em: 11 jun. 2019.

WILLIAMSON, O. E. The economics of organization: the transaction cost approach. The American Journal of Sociology, v. 87 n. 3, p. 548-577, 1981. DOI: 10.1086/227496

. Comparative economic organization: the analysis of discrete structural alternatives. Administrative Science Quarterly, v. 36 n. 2, p. 69-296, 1991. DOI: 10.2307/2393356

. Strategy Research: Governance and Competence Perspectives. Strategic Management Journal, v. 20, p. 1087-1108, 1999. DOI: 10.1002/(SICI)1097-0266(199912)20:12\%3C1087::AID-SMJ71\%3E3.0.CO;2-Z

WIZIACK, J.; CARNEIRO, M. Cade deve aprovar compra de XP pelo Itaú com restrições. Folha de São Paulo, 12 mar. 2018. Disponível em: <https://www1.folha.uol.com.br/mercado/2018/03/cade-deve-aprovar-compra-de-xp-pelo-itau-com-restricoes.shtml>. Acesso em: 9 abr. 2019. 